\title{
The Efficacy of Basic Sentence Pattern Approach for EFL Learners in Writing
}

\author{
Koh, Sungran ${ }^{1}$
}

\begin{abstract}
As a fundamental component of language, writing has been identified as the least proficient domain in acquiring a new language. Due to this universal idea, this research has been designed to find a more effective method to improve the writing skills of EFL learners and makes an attempt to investigate the effectiveness of a basic sentence pattern (BSP) drill through film corpus-based activities. To do this, as a pre-test, EFL learners were asked to make questionnaires with basic sentence patterns that translate Korean sentences into English to determine how much basic knowledge they had. For the questionnaires and the basic sentence pattern drill, the script of the American television series Modern Family (Lloyd \& Levitan, 2014) was collected and categorized into five basic sentence patterns. Then, the learners were taught about the 5 th basic sentence pattern, the most difficult pattern and were trained to practice this sentence pattern, repetitively, for a month. As a final step, they took a post-test after another month's training. The results show the overall score was enhanced significantly from pre-test to post-test. This finding demonstrates that basic sentence patterns can enable EFL learners to develop their sentence accuracy in writing.
\end{abstract}

Keywords: basic sentence patterns, EFL learner, foreign language, English writing, American TV series Applicable levels: secondary, tertiary

\footnotetext{
${ }^{1}$ Corresponding author, Lecturer, College of General Education, Kookmin University, 77 Jeongeung-ro, Seongbuk-gu, Seoul, 02707, Korea (E-mail: sungran@kookmin.ac.kr)

Received: October 14, 2021

Revised: November 16, 2021

Accepted: November 21, 2021
} 


\section{INTRODUCTION}

Writing ability in learning English has been an important domain to academic success and considered a great necessity for EFL learners for a long time. Writing has been one of the most mandatory skills since it strengthens grammatical structures and vocabulary that teachers attempt to teach their EFL students, and also the world has become text-oriented (Cole \& Feng, 2015). That is why students need to be proficient writers in a text-oriented world, but unfortunately it is particularly daunting for students learning English as a foreign language.

Bialystok and Ryan (1985) remark that there are many reasons for writing to be the last acquired area of learning English. There has been growing demand for effective techniques to improve writing skills in this population. Many researchers have studied effective strategies to teach English writing and to improve students' writing skills. Even so, English writing is still the most difficult and challenging part for EFL learners. Cole and Feng (2015) mention, "ESL students on all levels score lower in writing than any other domain. It is the last domain of second language learning to fully develop" (p. 6). Whereas EFL learners are able to communicate orally and use gestures to be understood, writing turns out to be discouraging and frustrating for EFL learners because they try to express their ideas with no means of using gestures. They do not feel confident and effective, but rather fearful to make errors and then lose more confidence.

There has been a lot of research on the sentence pattern method (SPM) as one of the effective writing instructions. Fries (1945) suggested that a guided and controlled writing method was based on behavioristic psychology, and good English writing is formed by right sentence patterns practice. Waddell, Esch, and Walker (1993) proposed the twenty patterns to learn English writing by imitating patterns. It showed the ability to write sentences improved by imitating English sentence patterns. Waddell et al. (1993) mentions, "You learn to write better sentences just the way you learn almost every other skill: by imitating the examples of those who already have that skill" (p. 1). He (2016) showed that basic sentence pattern drill has a great impact on EFL learners' writing achievement. Jayakumar (2010) stated that the sentence pattern method helped EFL learners to switch their thoughts into English sentences. Wong (1979) mentions that when the sentence pattern is fixed in EFL learners' brain, they boost their natural inclination to create new types of sentences.

Teaching the sentence pattern method is a sort of teaching grammar for EFL learners. Saun (2014) mentions that, "Grammar has never been fully deleted from teaching foreign languages... has been regarded or even appreciated as an important factor or element to be put into the curricular" (p. 386). Phuwarat (2020) demonstrates that grammar teaching helped ESL students improve English writing proficiency and emphasizes the importance of grammar instruction for EFL learners to improve their English writing. Ellis (2006) mentions that the role of grammar is a fundamental area of foreign language instruction in that it helps them improve in reading and listening as well as in writing skills.

On the other hand, Shaughnessy (1976) mentions that the most important thing in writing is make an atmosphere which encourages EFL learners to take risks in writing, which refers to less emphasis on conventional rules of writing and more on the expression of thought. To do so, instruction should not focus on the errors of writing and then permit EFL learners to express their ideas more freely. Jayakumar (2010) argues that teaching English grammar makes EFL learners lose interest in English learning. They feel grammar is an uninteresting area in English and even in their native language.

To overcome tedium while learning grammar and to boost EFL learners' learning efficacy, this study utilizes the American TV series Modern Family's (Lloyd \& Levitan, 2014) corpus-based patterns. Koh (2020) mentions, "sentence patterns method practice is that most of the communications in the movie are simple and compound sentences, not complex sentences" (p. 3). The EFL learner should use simple and compound sentences at first. The complex sentences lead to anxiety and doubt and can prevent the process of writing proficiently. In addition, EFL learners show a bigger interest in learning English through famous American dramas. Many studies have reported that dramas used in EFL classrooms draw their interest and can have a good impact on their desire to learn (Luo, 2004).

Also, in line with the teaching method approach, the present study suggests using the basic sentence pattern (BSP) approach in teaching English to EFL learners. This study utilizes the data of the 5th basic sentence pattern in American TV series Modern Family. There are two reasons for using the data. First, the prior investigation of this study shows 
that EFL learners consider longer and complex sentences even harder to make into English sentences. The 5th basic sentence pattern is the most complicated and complex of the five basic sentence patterns. Second, the 5th basic sentence pattern is more likely to be used in academic writing, and it could help improve English writing.

To do this, as a first step, the EFL learners' opinions on English writing were investigated: (a) What are the most difficult areas in English among four parts such as writing, speaking, listening, and reading? (b) Which part do you have the lowest confidence in English among four parts such as writing, speaking, listening, and reading? (c) What is the most challenging part of English writing? Next, EFL learners took a post-test of ten-part questionnaires using basic sentence patterns which change Korean sentences into English to assess their basic knowledge. After they were trained to practice the 5th basic sentence pattern among five sentence patterns repetitively for a month, they were taught about the 5 th basic sentence pattern. As a final step, they were asked to take a post-test after another month of training.

\section{LITERATURE REVIEW}

Grammar teaching has been a controversy, and researchers argue whether it should be taught as subject matter in foreign language. Celce-Murcia (2001) argues the significance of English grammar as a teaching method, emphasizing that grammar is a mandatory resource in translating accurate and effective communication. Azar (2007) states that students not knowing grammar have difficulty in understanding the principles of rhetoric that affect academic writing. Schulz (2001) also stresses grammar instruction and error correction and proposes that explicit feedback is an essential and effective approach to improve students' writing. Huan (2011) demonstrates that EFL learners' poor grammar knowledge leads to most of errors in college English writing and should not disregard grammar teaching when teaching English writing.

On the other hand, Saun (2014) asserts that teaching grammar is vital, but it may stunt the effort to use foreign language and should be made simple. Yano (1996) researches the effectiveness of the five sentence patterns in understanding English states that it is not important for EFL learners to classify English sentences into sentence patterns. This is because understanding the sentence meaning is more important than recognizing English sentence patterns in learning English. Koh (2020) mentions that English grammar is "a crucial part that has never been excluded in teaching English, but the point is whether to use the teaching method or approach which teaches grammar itself in class or using grammar as a medium to teach English through other approaches" (p. 3). Jayakumar (2010) notes that teaching English grammar to EFL learners results in a loss of interest in learning English and that it is good to use the sentence pattern method to create sentences.

Teaching sentence patterns, a part of English grammar has been regarded as doing wonders for improving EFL learners' skill. Yamazaki (1963) argues, "English sentence patterns are the frames or molds in which English words must be grasped... it is very important for English teaching and learning to identify the patterns and form and arrangement by which the words are put together" (p. 2). Yano (2012) proposes that English sentence patterns might be effectual in creating English sentences rather than understanding them. Hostmeyer (2013) demonstrates that teaching sentence patterns empowers the students to write sentences by adding, deleting and rearranging the components of sentences and create a wide range of patterns. When students understand the sentence patterns, they are able to imitate the original sentences into the new sentence patterns by adding or combining sentence elements and create further sentences through imitation. He (2016) states, "Basic sentence translation drills is valuable to develop students' writing ability, which is one of the effective ways of English writing teaching" (p. 146).

The five sentence patterns of English have been taught for EFL learners to explain the structure of English sentences. Researchers classify English sentence patterns into many different types. Waddell et al. (1993) classify English sentences into twenty sentence patterns while Quirk, Greenbaum, Leech, and Svartvik (1985) classify them into seven sentence patterns. Watanuki, Miyakawa, Sugai, and Takamatsu (2010) demonstrate five basic sentence patterns as follows. The present study will categorize and analyze sentence patterns of the corpora according to Table 1 because there is much previous research based on the five sentence patterns, and it is considered to be a reasonable method. 
TABLE 1

The Patterns of Simple Sentences (Watanuki et al., 2010, p. 34)

\begin{tabular}{lll}
\hline Pattern & Form & Example \\
\hline Pattern 1 & $\mathrm{~S}+\mathrm{V}$ & Everybody laughed. \\
Pattern 2 & $\mathrm{~S}+\mathrm{V}+\mathrm{C}$ & His eyes are blue. \\
Pattern 3 & $\mathrm{~S}+\mathrm{V}+\mathrm{O}$ & Foreigners admire Mt. Fuji. \\
Pattern 4 & $\mathrm{~S}+\mathrm{V}$ O1 $+\mathrm{O} 2$ & I gave him my address. \\
Pattern 5 & $\mathrm{~S}+\mathrm{V}+\mathrm{O}+\mathrm{C}$ & I found the box empty. \\
\hline
\end{tabular}

S: Subject; V: Verb; C: Complement; O: Object (O1: Indirect Object, O2: Direct Object)

Sundari (2013) shows that simple sentence patterns are basic structures that determine the ability to compose compound and complex sentences, and for EFL beginners, recognizing and understanding the English simple sentence patterns help develop paragraph and essay writing. Wishon and Burks (1980) present five sentence patterns having intransitive verbs, transitive verbs, certain transitive verbs (two objects and objective complements), and linking verbs. Sundari (2013) also shows the five basic patterns of simple sentences as shown in Table 2.

TABLE 2

The Patterns of Simple Sentences (Sundari, 2013, p. 4)

\begin{tabular}{|c|c|c|c|c|c|}
\hline Pattern & Subject & Verb & Object(s) & Complement & Adverb \\
\hline \multicolumn{6}{|l|}{ 1. Transitive Verbs } \\
\hline S-V & The door & opened & & & \\
\hline S-V-Adverb & My head & aches & & & all day \\
\hline 2. Transitive Verbs & & & & & \\
\hline $\begin{array}{l}\text { S-V-O } \\
\text { 3. Certain Transitive Verbs }\end{array}$ & The box & contains & pencils & & \\
\hline S-V-O-O & Tim & told & his friends & & \\
\hline 4. Certain Transitive Verbs & & & something & & \\
\hline S-V-O-Complement & The class & finds & Alice & a genius & \\
\hline 5. Linking Verbs & & & & & \\
\hline S-LV-Complement & Frank & is & & clever & \\
\hline
\end{tabular}

Sundari (2013) asserts that simple sentence patterns should be understood and recognized by EFL beginners because they are basic knowledge for practicing writing, and mastery of the sentence patterns boost their writing development. In this sense, basic sentence patterns for EFL learners have an important impact on the enhancement of language acquisition. The repetitive practice of particular fixed patterns can stimulate EFL learners' development in English writing. The more EFL learners accumulate the basic sentence patterns, the more they are apt to memorize and imitate. Gabrielatos (2002) mentions, "a traditional approach in which students are encouraged to mimic a model text, usually is presented and analyzed at an early stage" (p. 5). When EFL learners are provided with a standard sample of text as a beginner, they are able to follow the patterns to construct new sentences and develop their writing into paragraphs and essays. Saun (2014) mentions that sentence pattern approach in learning is the one of the ways of motivating EFL learners by not using tiring sentences.

Teaching writing through only traditional grammar could make EFL learners feel bored and diminish their willingness to participate in English writing drills. EFL learners need to have motivation and should not have the feeling of anxiety. In addition, Park (2019) mentions that the strong point of language learning using movies is their practical expressions. That is why this study makes use of the script for Season 6 of the American TV series Modern Family which premiered on September 24, 2014 on ABC on Wednesday nights. This relates several families' happenings and trials in their own comedic ways and is more likely to encourage the EFL learners to become independent learners. Also, it may arouse the EFL learners' motivation for writing English.

\section{METHODOLOGY}

This research was carried out among 50 EFL learners (male: $n=26$, female: $n=24$ ) who were freshman from English class as prerequisite courses in Seoul, Korea, and the participants were 19 to 22 years old. They have different 
majors such as civil and environmental engineering, advanced materials engineering and computer science, etc. At the beginning of the semester, EFL learners took a proficiency exam (TOEIC), and the students turned out being on the elementary level. This research was conducted within 10 weeks.

The corpus data of this study used an original English TV series, Modern Family. The data is from episode 21 to 24 of Season 6. One episode runs for around 20 minutes and they are totally around 80 minutes. The total number of sentences in four episodes are 160, which include only sentences. According to Sundari (2013), sentence is defined as "a group of words that contains at least subject + verb and has complete thought or meaning" (p. 2). Hence, one or two more words such as yes/no, right, okay, and so on are exempt from the data. The English subtitles data from the drama Modern Family was collected and sorted depending on the five patterns of simple sentences in Table 1. Then, the pattern 5 among the sorted data was analyzed for the most frequent five basic sentence patterns. The data was from the streaming service, Netflix.

This research is composed of four stages. The first stage investigates the EFL learners' opinion on English writing in a prior questionnaire: (a) What are the most difficult areas in English among writing, speaking, listening, and reading? (b) Which of these parts do you have the lowest confidence? (c) What is the most challenging part of English writing?

The next stage is conducted in two steps: pre-test and post-test. A pre-test was performed before drilling the EFL learners on pattern $5(\mathrm{~S}+\mathrm{V}+\mathrm{O}+\mathrm{C})$ among the five basic sentence patterns, they were asked to make sentences from Korean to English with five patterns in the orientation week. The pre-test was made up of pattern $1(\mathrm{~S}+\mathrm{V})$, pattern 2 $(\mathrm{S}+\mathrm{V}+\mathrm{C})$, pattern $3(\mathrm{~S}+\mathrm{V}+\mathrm{O})$, pattern $4(\mathrm{~S}+\mathrm{V}+\mathrm{I} . \mathrm{O}+\mathrm{D} . \mathrm{O})$ and pattern $5(\mathrm{~S}+\mathrm{V}+\mathrm{O}+\mathrm{C})$. The pre-test was composed of a total of ten questions which contained two sentences with each of five patterns. For example, there were two pattern $2(\mathrm{~S}+\mathrm{V}+\mathrm{C})$ questions such as Your speech was fantastic and It's so convenient. This pre-test was given to identify which sentence pattern among the five basic sentence patterns has the most frequent errors and was to decide the practice pattern of this study.

According to the pre-test, the most frequent errors were found in pattern 5. Hence, they were given the assignment to write ten basic sentence pattern 5 examples which had the most frequent errors in class and hand in the assignments in the next class. Then, they were instructed to correct their wrong sentences focusing on the sentence patterns according to the given answers with the proper explanation about the sentence patterns. These procedures were performed repeatedly from week 1 to week 8 . After they were trained by writing different sentences with the similar sentence pattern for two months, they took a post-test by making sentences using the sentence pattern. Some tricky vocabulary was provided in the questions based on their vocabulary knowledge. The data was gathered and evaluated by a native English speaker and researchers for reliability. This evaluation was conducted mainly focusing on the basic sentence patterns, not considering spelling mistakes or wrong article usage.

The final stage used a post questionnaire with two question items to ask EFL learners their opinion on basic sentence pattern practice. This stage is to identify their recognition and understanding of the sentence pattern and to seek out their feelings when making sentences using basic sentence patterns. The questionnaire was in a descriptive format to explain their opinions comfortably in their first language, Korean.

\section{RESULTS AND DISCUSSION}

\section{Prior Questionnaire}

Before teaching the writing class, a questionnaire was given to identify EFL learners' English difficulties and English writing problems. The questionnaire was composed of the following: a) What do you think is the most difficult part of English? b) What do you think is your weakest point in English? c) What is the most difficult part of English writing? The results for each item of the questionnaire are as follow.

\section{1) What Do You Think Is the Most Difficult Part of English?}

The questionnaire consists of four parts such as speaking, writing, reading, and listening. EFL learners have the 
most trouble with the writing part of English at 37\%. English speaking rates second, followed by reading and listening. It is clear that ELF learners are in great need to of learning how to write English effectively and efficiently.

FIGURE 1

The Most Difficult Part of English

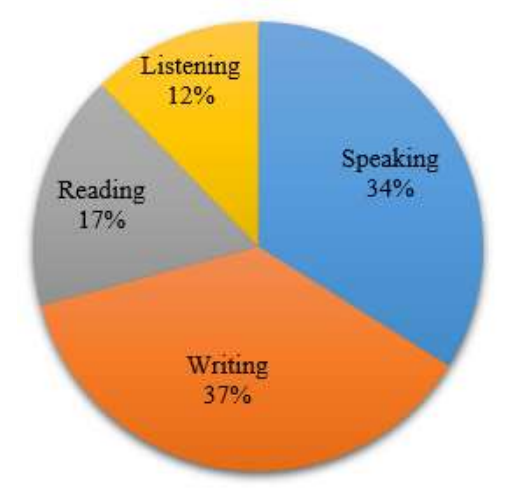

\section{2) What Do You Think Is Your Weakest Point in English?}

The result shows that EFL learners think speaking is their weakest point in English. This implies that they think they can achieve English speaking even though they think it is their weakest point in that more EFL learners responded that writing is the most difficult part of English. Reading is in third place, followed by listening as in the first question. EFL learners think listening is the least difficult and weakest field in English learning.

\section{FIGURE 2}

Their Weakest Point in English

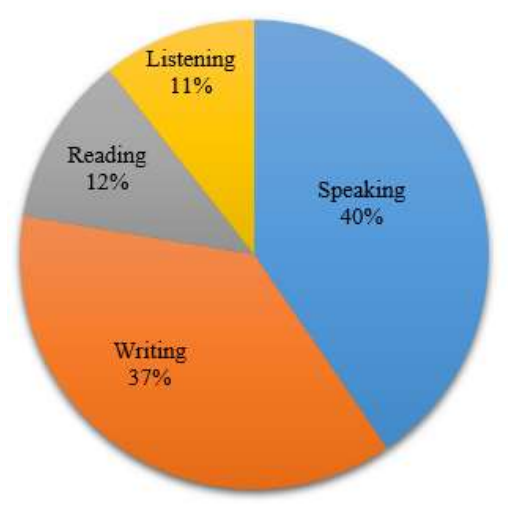

\section{3) What Is the Most Difficult Part of English Writing?}

EFL learners think the most difficult part of English writing is the lack of vocabulary. They think they don't have enough vocabulary and that they have poor knowledge of English grammar, especially prepositions, verbs, and conjunctions. This is why teaching grammar is essential for writing in the form of sentence patterns or formulas. It is essential to facilitate their writing skill even though many EFL learners find grammar difficult and boring. 
FIGURE 3

The Most Writing Difficulties

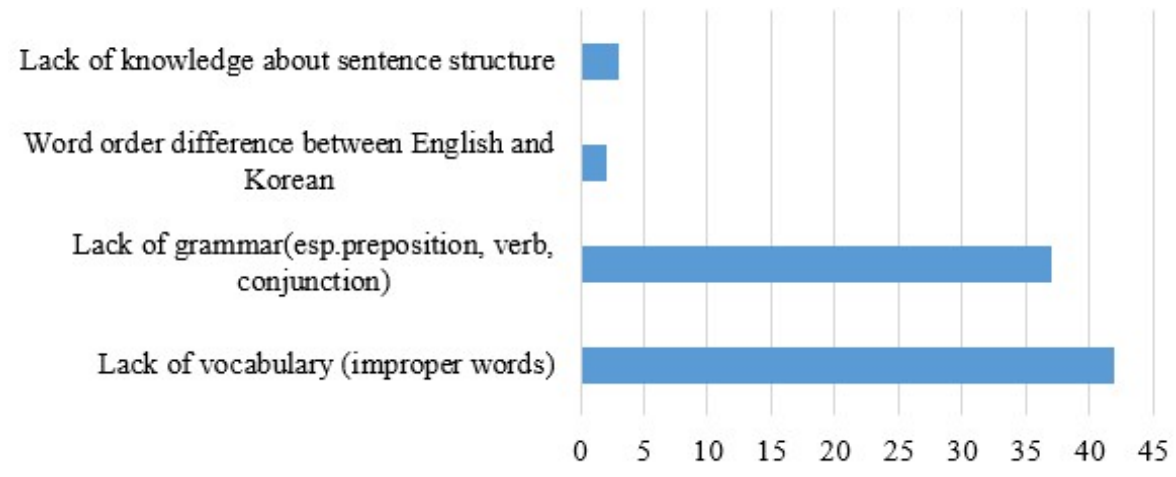

\section{The Five Basic Sentence Patterns Prior Examination}

\section{1) Analysis of Prior Examination Scores}

The corpus data from the English TV series, Modern Family was categorized into five basic English sentence patterns. The data was previously tested with EFL learners writing from Korean into English. As shown in Figure 4, pattern 5 is at the lowest point among five basic patterns.

FIGURE 4

Five Basic Sentence Patterns in Prior Examination

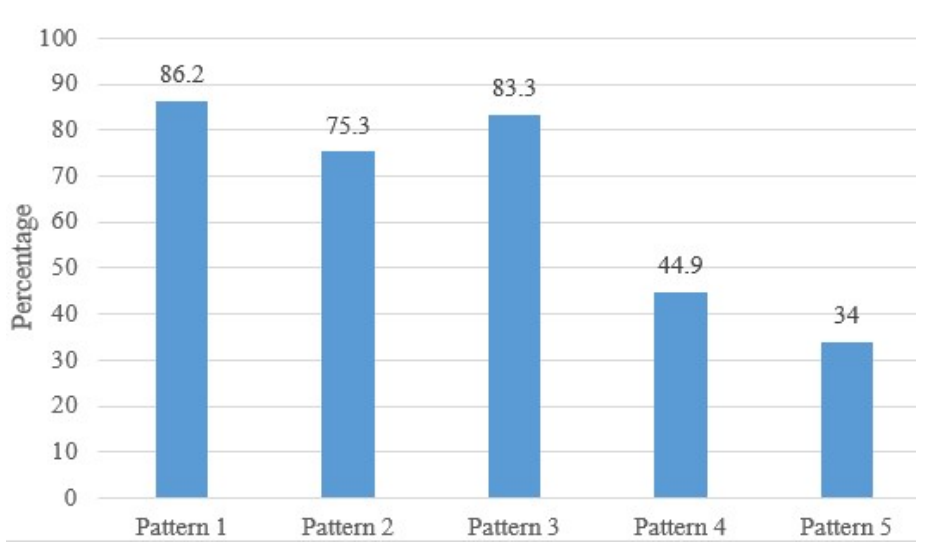

The pattern 5 sentences in the pre-test were verb + object + to base form verb. In the questionnaire where the answer is She wants me to propose, many EFL learners did not understand the structure and answered wrong such as She wants to me propose, She want that I propose, She want propose me, She want propose which I do, She wants to me that I propose to her, and She want to that I will ask her for marry me.

\section{2) Categorization of the Data and Sentence Practice}

The most frequent verbs are put into eleven categories from the data of the English TV series, Modern Family. The most frequent verb was want $+\mathrm{O}+$ to base form verb. Figure 5 shows the order of the frequent verbs. 
FIGURE 5

The Order of Frequent Verbs

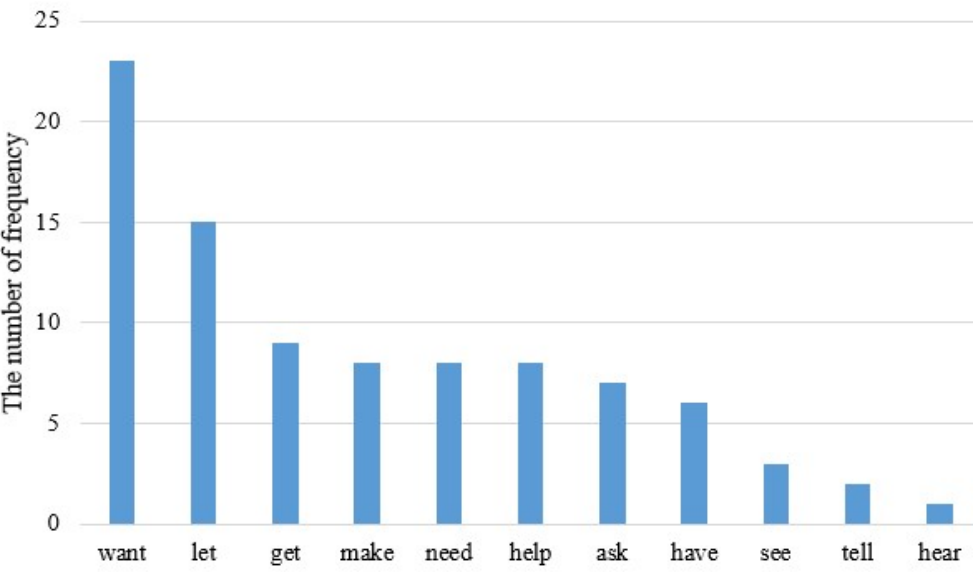

The above frequent verbs are categorized into three patterns among the 5 th sentence pattern: a) verb + object + base form verb, $\mathrm{b})$ verb + object + to base form verb, c) verb + object + p.p. The findings gathered as follow in Table 3 .

TABLE 3

Categorization of Basic Sentence Patterns

\begin{tabular}{lll}
\hline a) verb + object $(\mathrm{O})+$ base form & b) verb + object + to base form & c) verb + object + past participle $(\mathrm{p} . \mathrm{p})$ \\
\hline let $+\mathrm{O}+$ base form verb & get $+\mathrm{O}+$ to base form verb & have $+\mathrm{O}+\mathrm{p} . \mathrm{p}$ \\
have $+\mathrm{O}+$ base form verb & ask $+\mathrm{O}+$ to base form verb & get $+\mathrm{O}+\mathrm{p} . \mathrm{p}$ \\
make $+\mathrm{O}+$ base form verb & help $+\mathrm{O}+$ to base form verb & see $+\mathrm{O}+\mathrm{p} . \mathrm{p}$ \\
hear $+\mathrm{O}+$ base form verb & tell $+\mathrm{O}+$ to base form verb & hear $+\mathrm{O}+\mathrm{p} . \mathrm{p}$ \\
& want $+\mathrm{O}+$ to base form verb & \\
& need $+\mathrm{O}+$ to base form verb & \\
\hline
\end{tabular}

According to these patterns, this research was carried out for eight weeks. From the first week to the fifth week, EFL learners changed Korean sentences into English and were directed to write using given words such as let, have, make, ask and so on with no teaching about sentence patterns. Then, the sentence patterns above in Table 3 were introduced from the sixth week to the eighth week. Table 4 shows the training plan for eight weeks. As shown in Table 4, the verb sentence patterns were practiced more than twice.

TABLE 4

Training Plan for Sentence Patterns

\begin{tabular}{|c|c|c|}
\hline Week & \multicolumn{2}{|c|}{ Training Contents } \\
\hline Week 1 & let $+\mathrm{O}+$ base form verb & hear $+\mathrm{O}+$ base form verb \\
\hline Week 2 & $\begin{array}{l}\text { make }+\mathrm{O}+\text { base form verb } \\
\text { get }+\mathrm{O}+\text { to base form verb }\end{array}$ & $\begin{array}{l}\text { let }+\mathrm{O}+\text { base form verb } \\
\text { have }+\mathrm{O}+\text { base form verb }\end{array}$ \\
\hline Week 3 & $g e t+\mathrm{O}+$ to base form verb & get $+\mathrm{O}+$ past participle \\
\hline Week 4 & $\begin{array}{l}\text { make }+\mathrm{O}+\text { base form verb } \\
\text { have }+\mathrm{O}+\text { base form verb }\end{array}$ & $\begin{array}{l}\text { ask }+\mathrm{O}+\text { to base form verb } \\
\text { want }+\mathrm{O}+\text { to base form verb }\end{array}$ \\
\hline Week 5 & $\begin{array}{l}\text { have }+\mathrm{O}+\text { past participle } \\
\text { tell }+\mathrm{O}+\text { to base form verb }\end{array}$ & let $+\mathrm{O}+$ base form verb \\
\hline Week 6 & $\begin{array}{l}\text { ask }+\mathrm{O}+\text { to base form verb } \\
\text { hear }+\mathrm{O}+\text { base form verb }\end{array}$ & need $+\mathrm{O}+$ to base form verb \\
\hline Week 7 & $\begin{array}{l}\text { have }+\mathrm{O}+\text { past participle } \\
\text { tell }+\mathrm{O}+\text { to base form verb } \\
\text { help }+\mathrm{O}+\text { to base form verb }\end{array}$ & $\begin{array}{l}\text { let }+\mathrm{O}+\text { base form verb } \\
\text { want }+\mathrm{O}+\text { to base form verb }\end{array}$ \\
\hline Week 8 & $\begin{array}{l}\text { have }+\mathrm{O}+\text { past participle } \\
\text { tell }+\mathrm{O}+\text { to base form verb } \\
\text { have }+\mathrm{O}+\text { base form verb }\end{array}$ & $\begin{array}{l}\text { let }+\mathrm{O}+\text { base form verb } \\
\text { help }+\mathrm{O}+\text { to base form verb }\end{array}$ \\
\hline
\end{tabular}


The EFL learners' correction answer scores from week 1 until week 8 are collected. The finding shows that the lowest scores are from the sentence pattern get $+O+$ to base form verb and get $+O+$ past participle in week 3 as shown in Figure 6. The total correct answer score is 500 and the correct answer scores shown in Figure 6 are average scores of all EFL learners each week.

\section{FIGURE 6}

Correct Answer Scores

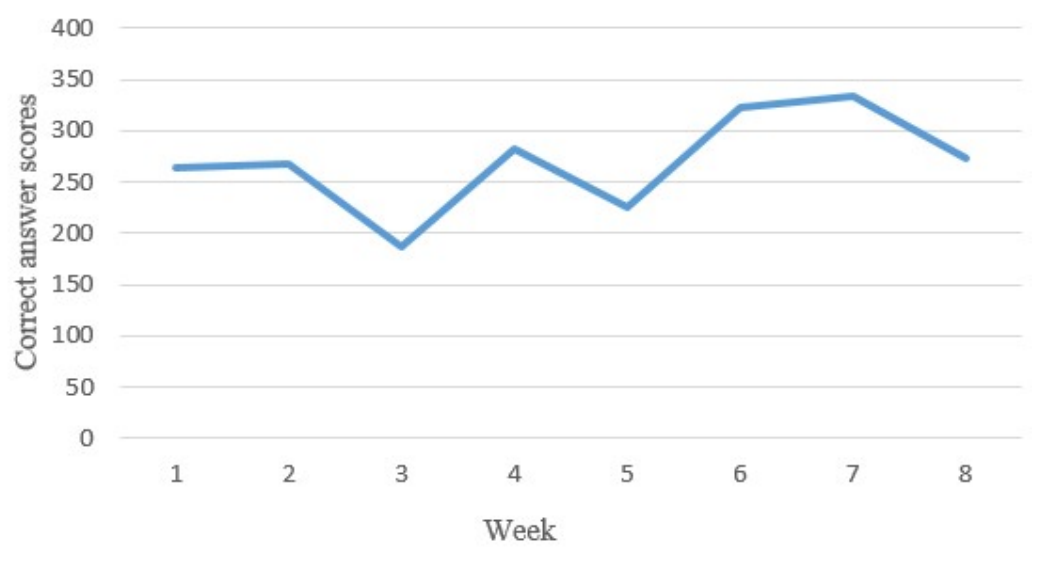

\section{3) Comparison and Analysis of the Pre-Test and Post-Test Scores}

A paired $t$-test was performed to compare the scores of the pre-test and the post-test so as to find out whether basic sentence pattern activities are useful in improving students' writing ability. Table 5 demonstrates paired analysis for the EFL learners.

TABLE 5

Descriptive Statistics Comparing Pre-Test and Post-Test

\begin{tabular}{ccccccc}
\hline & $N$ & $M$ & $S D$ & $t$ & $d f$ & 18 \\
Pre-test & 50 & 48 & 14.89 & $<0.05$ & -1.94 \\
Post-test & 50 & 60.80 & 13.09 & & \\
\hline
\end{tabular}

As seen in Table 5, the overall score between the pre-test and post-test improved from pre-test to post-test (pretest: $M=48, S D=14.89$; post-test: $M=60.80, S D=13.09 ; t=<0.05, p=-1.94$ ). The scores of the post-test are obviously higher than those of the pre-test. It can be demonstrated that BSP has a positive influence on the ability to improve writing achievement with linguistic patterns.

TABLE 6

Pre-Test and Post-Test

\begin{tabular}{|c|c|c|c|}
\hline \multirow{2}{*}{ Test Number } & \multirow{2}{*}{ Training Contents } & \multicolumn{2}{|c|}{ Correct Answer Ratio } \\
\hline & & Pre-test & Post-test \\
\hline 1 & have $+\mathrm{O}+$ past participle & 50 & 52 \\
\hline 2 & make $+\mathrm{O}+$ base form verb & 22 & 64 \\
\hline 3 & let $+\mathrm{O}+$ base form verb & 76 & 82 \\
\hline 4 & get $+\mathrm{O}+$ past participle & 60 & 50 \\
\hline 5 & get $+\mathrm{O}+$ to base form verb & 58 & 60 \\
\hline 6 & ask $+\mathrm{O}+$ to base form verb & 40 & 40 \\
\hline 7 & $b e g+\mathrm{O}+$ to base form verb & 46 & 48 \\
\hline 8 & tell $+\mathrm{O}+$ to base form verb & 28 & 60 \\
\hline 9 & want $+\mathrm{O}+$ to base form verb & 46 & 76 \\
\hline 10 & need $+\mathrm{O}+$ to base form verb & 54 & 76 \\
\hline
\end{tabular}


The pre-test and post-test EFL learners' data was collected and analyzed. Both of the tests are comprised of the same ten questions. As shown in Table 6, the result shows that most test items improved except for question number four, the get $+O+$ past participle pattern. EFL learners found the get $+O+$ past participle pattern/ to base form verb difficult as shown in above Figure 5 and 6 as well.

Question number one have $+O+$ past participle improved the least followed by the get $+O+$ past participle pattern. The common point is that both have a past participle pattern. Past participle having a passive meaning is one of the difficult grammar details for Korean EFL learners because their native language does not have a past participle pattern which is in the passive form. Rustipa (2016) called this an interlingual error in which native language results in the EFL learners' confusion and mistakes.

The most improved BSP are questions number two make $+O+$ base form verb, number eight, tell $+O+$ to base form verb, and question number nine want $+O+$ to base form verb. Using the base form verb seems much easier, and Korean EFL learners are used to putting them into use. (see in Figure 7)

FIGURE 7

\section{Comparison of Pre-Test With Post-Test Ratio}

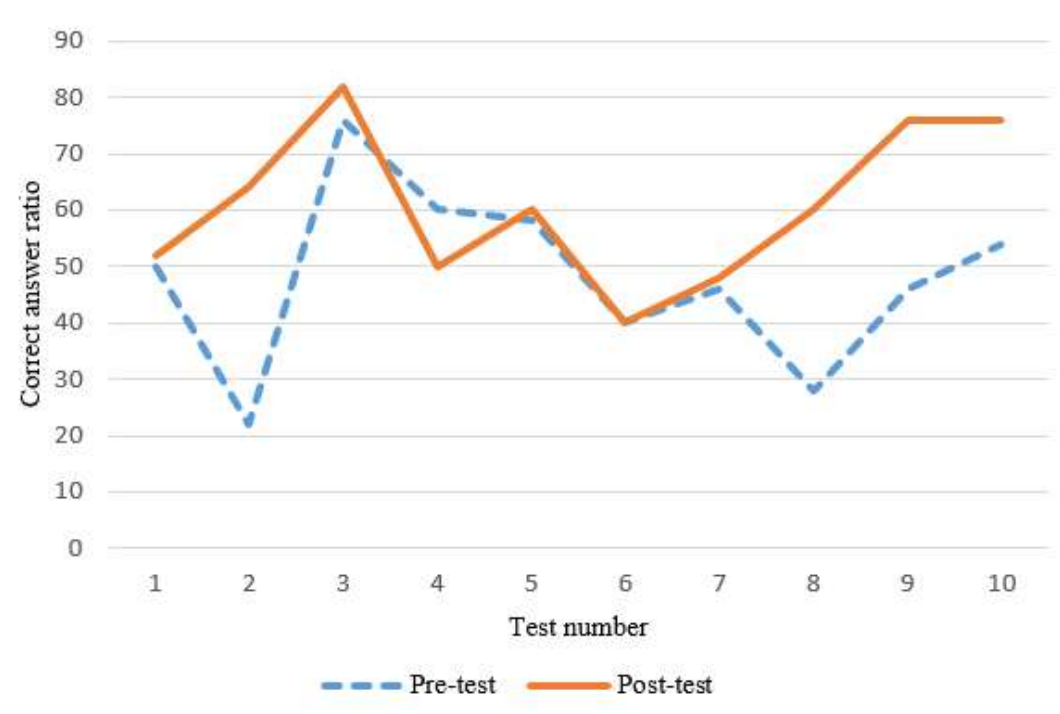

Overall, the result demonstrates that the ability of Korean EFL learners to write in the English language developed through basic sentence pattern training with a media corpus-based pattern drill. However, the findings show that a few test item scores in the posttest rather dropped over the pre-test. In this research, the reasons are analyzed as an interlanguage effect.

\section{Post Questionnaire}

This questionnaire is used to find whether the EFL learners feel their English writing ability improved and developed and their opinion on making sentences using basic sentence patterns. The questionnaire is made up of two questions: one multiple choice question and one short-answer question. The multiple choice question is as follows: Basic sentence pattern drill is helpful and useful in writing English sentences. The range of responses for this item is from agree to disagree. Most of them ticked agree that basic sentence pattern training is helpful and useful in writing English sentences. Therefore, they tend to be consistent with the above result. The results for this item of the questionnaire are as follows in Figure 8: 


\section{FIGURE 8}

Q: Basic Sentence Pattern Drill Is Helpful and Useful in Writing English Sentences.

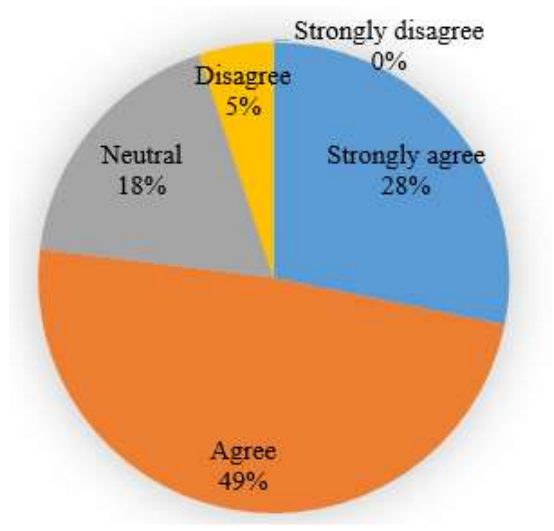

Next is the short- answer question: If the basic sentence pattern drill is/ isn't helpful and useful in writing English sentences, describe the reason for it in detail and your other opinions, etc. The EFL learners responded to the survey and the opinions were categorized and divided into seven categories. Table 7 summarizes their opinions regarding the effectiveness of sentence pattern practice in their learning activities.

TABLE 7

The Positive Opinions on the Instruction

\begin{tabular}{lc}
\hline \multicolumn{1}{c}{ Response } & Percentage (\%) \\
\hline 1. Improving to complete sentences & 36 \\
2. Understanding how to make sentences & 25 \\
3. Having confidence & 14 \\
4. Understanding the basic knowledge of sentence structures & 11 \\
5. Understanding the precise usages of the words & 7 \\
6. Understanding the useful grammar to make sentences & 3 \\
7. Saving time & 4 \\
\hline
\end{tabular}

As seen in Table 7, 36\% of the positive opinion responses were such as While I've practiced sentence pattern English writing, I felt my ability to complete sentences with basic sentence patterns is improved and I feel my English writing has developed as I've practiced more. However, some EFL learners responded in a negative way such as $I t$ was interesting experience and was difficult than I had expected and Sentence pattern practice seems to be useful, but it was a difficult point to use only specific words.

\section{CONCLUSION}

This study is an attempt to investigate the effectiveness of the basic sentence pattern drill through media corpusbased activities. The investigation demonstrates that instruction through the basic sentence pattern drill can effectively develop EFL learners' sentence writing ability. Thus, the basic sentence pattern approach to teaching sentence writing would be one step of an alternative method that is offered to the EFL learners.

Most of the EFL learners not only improved in writing English but also had more confidence in making sentences. Practice of the basic sentence patterns can more quickly and efficiently lead to mastery of a foreign language and the ability to recognize, arrange, understand, and write simple sentences and then to develop and combine compound and complex sentences. It would also help develop paragraphs, essays, and advanced writing.

The basic sentence pattern approach is also another method to learn grammar by repeatedly recognizing sentence patterns and combining sentence patterns as an EFL learner mentioned in the self-reflection such as I was confused about the structures of five sentence patterns from time to time, but in this opportunity, I came to be definitely able to learn and memorize them. Andrews et al. (2005) states that the teaching of traditional grammar is not effective, but the indirect teaching of grammar is. Therefore, basic sentence pattern drills enable EFL learners to acquire foreign 
language more deeply, which will enhance their understanding of language accuracy. The deeper sentence understanding of foreign language influences the EFL learners' capability in writing precise sentences.

Jayakumar (2010) states, "Knowing the English sentence patterns for Tamil situations played a major role in enhancing the students' spoken English fluency" (p. 209). It should be applied to writing English. This paper suggests the basic sentence pattern drill for teaching written English to Korean EFL learners. The basic sentence pattern drill helped EFL learners to turn Korean into English sentence structure easily and with confidence.

Also, the fifth sentence pattern drill is suggested for developing their written English in a short time while learning simple grammar. It is also supported by Saun's (2014) remark, "Teaching grammar must be made simple and fun. If not made simple and fun, it will also block fluency" (p. 392). Kashiwagi and Ito (2017) mention, "Teacher must ensure that students do not rely on the rule but that they instead use 'imitating', 'repeating', 'borrowing', and 'replacing parts of chunks' (increasing both token and type frequency) to form language slots that students can access rapidly" (p. 65). The 'imitating' and 'repeating' which are the major strategies of this basic sentence pattern drill play a crucial role in foreign language acquisition. By imitating the already acquired patterns, EFL learners master the skill of writing well and expand their sentences with grace and style.

As seen before, the Korean EFL learners' difficulty according to this result is the past participle having a passive meaning. Tarone (2006) mentions that interlanguage is made reference to as a characteristic of EFL learners who already have fixed their native language. Since their native language, Korean, does not have the past participle pattern, they have difficulty in using the past participle form. Consequently, it leads to awkward and misused expressions in English. For Korean EFL learners, the repetitive practice and drill are required for them to write more smoothly and naturally.

Koh (2020) asserts, "The importance of the teacher's role cannot be over emphasized in teaching foreign language. Language teachers should be able to make the most use of the corpus-based material and introduce practical clues" (p. 14). To improve the writing skills of EFL learners' in English, it is suggested that teachers should consider new and innovative methods for their teaching and a more fruitful and balanced approach should be applied.

\section{REFERENCES}

Andrews, R., Zhu, D., Robinson, A., Low, G., Locke, T., Freeman, A., \& Torgerson, C. (2005). The effect of grammar teaching (sentence combining) in English on 5 to 16 year olds' accuracy and quality in written composition: Review summary. York, England: University of York, Dept. of Educational Studies. Retrieved from https://citeseerx.ist.psu.edu/viewdoc/download?doi=10.1.1.368.6443\&rep=rep1\&type=pdf

Azar, B. (2007). Grammar-based teaching: A practitioner's perspective. TESL-EJ, 11(2), 1-12. Retrieved from https://files.eric.ed.gov/fulltext/EJ1064995.pdf

Bialystok, E., \& Ryan, E. (1985). A metacognitive framework for the development of first and second language skills. In D. F. Pressley, G. Mackinnon, \& T. G. Wallers (Eds.), Metacognition, cognition, and human performance (pp. 207-252). New York, NY: Academic Press.

Celce-Murcia, M. (2001). Teaching English as a second or foreign language. Boston, MA: Heinle \& Heinle.

Cole, J., \& Feng, J. (2015, April 15-16). Effective strategies for improving writing skills of elementary English language learners. Paper presented at the Chinese American Educational Research and Development Association Annual Conference, Chicago, IL. Retrieved from https://files.eric.ed.gov/fulltext/ED556123.pdf

Ellis, R. (2006). Current issues in the teaching of grammar: An SLA perspective. TESOL Quarterly, 40(1), 83-107. https://doi.org/10.2307/40264512

Fries, C. (1945). Teaching and learning English as a second language. Ann Arbor, MI: University of Michigan Press. Gabrielatos, C. (2002). EFL writing: Product and process (ED476839). ERIC. Retrieved from https://files.eric.ed.gov/fulltext/ED476839.pdf

He, X. (2016). An action research on improving non-English majors' English writing by basic sentence pattern translation drills. English Language Teaching, 9(1), 142-147. https://doi.org/10.5539/elt.v9n1p142 
Hostmeyer, P. (2013). Tools students need to be skillful writers: Building better sentences. Thousand Oaks, CA: Corwin Press. https://doi.org/10.4135/9781506335469

Huan, W. (2011). An analysis of errors in college English writing in China. Sino-US English Teaching, 8(6), 369-375. Jayakumar, K. S. (2010). Sentence pattern method: A new approach for teaching spoken English for Tamil/Indian/ EFL learners. Language in India, 10(11), 202-212. Retrieved from http://www.languageinindia.com/nov2010/v10i11 nov2010.pdf

Kashiwagi, K., \& Ito, Y. (2017). EFL learners' grammatical awareness through accumulating formulaic sequences of morphological structure (-ing). English Language Teaching, 10(11), 60-75. https://doi.org/10.5539/elt.v10n11p60

Koh, S. R. (2020). Initial formulaic sequence approach for EFL learners: Based on film corpus-based patterns. STEM Journal, 21(4), 1-17. https://doi.org/10.16875/stem.2020.21.4.1

Lloyd, C., \& Levitan, S. (Executive Producers). (2009-2020). Modern family [Television series]. Los Angeles, CA: Picador.

Luo, J. J. (2004). Using DVD films to enhance college freshmen's English listening comprehension and motivation (Unpublished master's thesis). National Tsing Hua University, Hsinchu City, Taiwan, R.O.C.

Park, Y. (2019). A study on the status of movie English in the EFL classroom. STEM Journal, 20(4), 83-101. https://doi.org/10.16875/stem.2019.20.4.83

Phuwarat, C. (2020). The role of grammar teaching in ESL writing. Sripatum Chonburi Journal, 16(4), 1-9. Retrieved from https://so05.tci-thaijo.org/index.php/SPUCJ/article/view/244110

Quirk, R., Greenbaum, S., Leech, G., \& Svartvik, J. (1985). A comprehensive grammar of the English language. London: Longman.

Rustipa, K. (2016). EFL students' writing accuracy: Can text analysis develop it? International Journal of English Linguistics, 7(1), 126-136.

Saun, S. (2014). The sentence pattern approach in teaching the English tenses: Problems in achieving the communicative goals. The Proceedings of International Seminar on English Language and Teaching, 2(4), 386-393. Retrieved from http://ejournal.unp.ac.id/index.php/selt/article/view/6731

Schulz, R. A. (2001). Cultural differences in student and teacher perceptions concerning the role of grammar instruction and corrective feedback: USA-Colombia. The Modern Language Journal, 85(2), 244-258. https://doi.org/10.1111/0026-7902.00107

Shaughnessy, M. P. (1976). Diving in: An introduction to basic writing. College Composition and Communication, 27(3), 234-239. https://doi.org/10.2307/357036

Sundari, H. (2013). Mastery of simple sentence patterns in writing class: A case study of third semester college students. English Education, 1(3), 1-11.

Tarone, E. (2006). Interlanguage. In K. Brown (Ed.), The encyclopedia of language and linguistics (pp. 747-752). Boston, MA: Elsevier.

Waddell, M., Esch, R., \& Walker, R. (1993). The art of styling sentences: 20 patterns for success. New York, NY: Barron.

Watanuki, Y., Miyakawa, Y., Sugai, T., \& Takamatsu, N. (2010). Royal English grammar with complete examples of usage. Tokyo: Obunsha.

Wishon, G. E., \& Burks, J. M. (1980). Let's write English. New York, NY: American Book.

Wong, F. L. (1979). Individual differences in second language acquisition. In C. Fillmore, D. Kempler, \& W. Wang. (Eds.), Individual differences in language ability and language behavior (pp. 203-228). New York, NY: Academic Press.

Yamazaki, S. (1963). English sentence patterns and sentence analysis in American structural linguistics. Journal of the Faculty of Textile Science and Technology, Shinshu University. Ser. D, Arts, 6, 1-37. Retrieved from https://core.ac.uk/download/pdf/148779054.pdf

Yano, J. (1996). The usefulness of five sentence patterns in understanding English (Unpublished master's thesis). Tokyo Gakugei University, Tokyo, Japan. 